https://helda.helsinki.fi

\title{
Minimal Truthmakers
}

\section{O'Conaill, Donnchadh}

2016-06-01

O'Conaill , D \& Tahko , T E 2016 , ' Minimal Truthmakers ', Pacific Philosophical Quarterly , vol. 97 , no. 2 , pp. 228-244 . https://doi.org/10.1111/papq.12064

http://hdl.handle.net/10138/166157

https://doi.org/10.1111/papq.12064

submittedVersion

Downloaded from Helda, University of Helsinki institutional repository.

This is an electronic reprint of the original article.

This reprint may differ from the original in pagination and typographic detail.

Please cite the original version. 


\title{
MINIMAL TRUTHMAKERS
}

\author{
Donnchadh O’Conaill and Tuomas E. Tahko
}

Penultimate draft, April 23, 2014.

Final version forthcoming in Pacific Philosophical Quarterly.

\begin{abstract}
A minimal truthmaker for a given proposition is the smallest portion of reality which makes this proposition true. Minimal truthmakers are frequently mentioned in the literature, but there has been no systematic account of what they are or of their importance. In this paper we shall clarify the notion of a minimal truthmaker and argue that there is reason to think that at least some propositions have minimal truthmakers. We shall then argue that the notion can play a useful role in truthmaker theory, by helping to explain the truth of certain propositions as precisely as possible.
\end{abstract}

Minimal truthmakers are frequently mentioned in the literature, and have been referred to as being 'of quite special importance for metaphysics' (Armstrong 2004, 19). However, there has been no systematic account of what minimal truthmakers are, or a specification of why they are so important. In this paper we make a start on a systematic treatment of these issues. We shall provide an overview of the rather fragmentary literature on minimal truthmakers and suggest a number of improvements to the definition and application of this notion. After sketching a general account of truthmaking (section I), we shall consider how minimal truthmakers might be defined (section II). We shall then argue that at least some propositions, for instance those which concern fundamental particles such as electrons, plausibly have 
minimal truthmakers (section III). In section IV we shall briefly assess the reasons Armstrong gives for regarding minimal truthmakers as important for metaphysics, and suggest that they are not convincing. In sections V and VI, we shall show how minimal truthmakers can explain the truth of specific propositions in as precise a manner as possible, and so meet an important desideratum of truthmaker theory. In section VII we shall consider some possible objections to our position.

\section{I}

We assume that truthmaking is a legitimate and fruitful approach to various philosophical issues, and so will not attempt to provide either a general defence or a detailed explication. ${ }^{1}$ Our argument is conditional: if it is accepted that truthmaking is a useful approach in metaphysics, then one promising way to develop it is in terms of minimal truthmakers.

We shall work with a notion of truthmaking formulated in terms of a primitive 'in virtue of' locution, which produces a familiar truthmaker principle:

(TM) Necessarily, if a proposition $p$ is true and has a truthmaker, then there is some entity in virtue of which it is true. ${ }^{2}$

Truthmaking thus formulated entails (though is not the same as) necessitation: the existence of a truthmaker is sufficient for the truth of those propositions it makes true. Truthmaking is not a one-one relation: a proposition can have many truthmakers, and an entity can make many propositions true. We can also differentiate between full and partial truthmakers. Consider the proposition 'There exists a set of all green things'. This proposition is partially made true by the greenness of each green thing, but no proper subset of green things can make the proposition true - only the greenness of all the green things together can fully 
make the proposition true. So we may conclude that each green thing is a partial truthmaker for the above proposition, and all green things together are its full truthmaker. ${ }^{3}$

We do not wish to commit ourselves to a particular ontology of truthmakers (as facts, substances, true propositions, etc.). In what follows, we will frequently give as examples of truthmakers facts or states of affairs, but we will do so largely for ease of exposition.

Before moving on, there is one other feature of (TM) which is worth considering, in part because it might be thought to provide a quick argument to the conclusion that there must be minimal truthmakers. 'In virtue of' relations are widely understood to be non-monotonic (e.g., Rodriguez-Pereyra 2000, 264; 2006, 973). Therefore, if we understand truthmaking in terms of an 'in virtue of' relation, then we are committed to denying the following thesis of monotonicity with regard to truthmaking:

(M): If $x$ makes $p$ true, and $x$ is included in $y$, then $y$ makes $p$ true (Simons 1992, 165).

It may seem that if truthmaking is understood in terms of an 'in virtue of' relation, each truthmaker is a minimal truthmaker. If $x$ makes $p$ true, and truthmaking is non-monotonic, then the suggestion might be that $x$ cannot have any proper part which makes $p$ true. There would then be no need to define minimal truthmakers in addition to this understanding of truthmaking. ${ }^{4}$

However, we think this argument does not work. ${ }^{5}$ To deny $(\mathrm{M})$ is to deny that every whole is a non-minimal truthmaker for every proposition made true by its proper parts. But to deny this is not to deny that there are some wholes which are truthmakers for at least some of the propositions made true by their proper parts. Therefore, it does not follow from denying (M) that there cannot be non-minimal truthmakers, or that no truthmaker $x$ for a proposition $p$ can belong to a more widely-encompassing entity $y$ which also makes $p$ true. 
We suggest that whether a proposition with a minimal truthmaker also has non-minimal truthmakers is best decided on a case-by-case basis. For example, consider the proposition 'Paris is the capital of France and it is snowing'. In this case, we would agree with RodriguezPereyra that the truthmaker for this conjunctive proposition does not make either of its conjuncts true (2006, 970-971). However, we do not think this holds true of all conjunctive propositions. In the case of the proposition 'The ball is round and the ball is red', we would say that the ball's overall physical state is a full truthmaker for the conjunctive proposition and for each of the conjuncts (as are, respectively, the ball's shape and its colour). Unlike in the first case, we take it that the overall physical state of the ball is clearly relevant to truths about its shape and colour, and so is a non-minimal truthmaker for these truths.

II

Armstrong introduces the notion of a minimal truthmaker as follows: 'If $\mathrm{T}$ is a minimal truthmaker for $p$, then you cannot subtract anything from $\mathrm{T}$ and the remainder still be a truthmaker for p' (2004, 19-20). Given the distinction between full and partial truthmakers, a minimal truthmaker for a given proposition can be understood as the smallest or least encompassing portion of reality that fully makes the proposition true. One way to make this idea more precise would be as follows:

D1: $T$ is a minimal truthmaker for $p={ }_{\mathrm{df}} T$ fully makes $p$ true and either (i) $T$ is such that it has no proper parts, or (ii) no proper part of $T$ fully makes $p$ true. $^{6}$

D1 is a popular way of understanding minimal truthmakers, but it suffers from a potential weakness. The intuitive idea of 'minimal' in this context is something like the least encompassing portion of reality. However, portions of reality may include things which are 
not, on the classical mereological conception of parthood, parts of anything, e.g., properties, relations, etc. Such portions might be more or less encompassing but not differ regarding their parts. This issue has been noted by Armstrong himself: his example is states of affairs, which have constituents (particulars and properties) but which are composed in a non-mereological fashion $(2004,18)$. As long as minimal truthmakers are characterised in terms of classical partwhole relations, the notion will be inapplicable to states of affairs, or to any entities which can only be understood in terms of non-mereological composition. ${ }^{7}$

There are a number of possible responses to this problem, of which we shall outline two. The first response would be to retain D1 but rethink the notion of parthood it employs. A more liberal alternative to the classical notion of 'part' has recently been defended by Kit Fine:

When one object is a part of another, there is a sense in which it is in the other-not in the sense of being enclosed by the other, as when a marble is in an urn, but more in the sense of being integral to the other. When parts are in question, it is also appropriate to talk of a given object being composed of or built up from the objects that it contains (2010, 560).

Fine notes that all manner of things, from sentences to symphonies to sets, are composed of other things. Accordingly, he proposes to define the general relation of part in terms of the operation of composition: 'The parts of an object are the object itself, or its components, or the components of the components, and so on' (2010, 567-568). Fine defines the general relation of parthood more precisely (e.g. the relation is plausibly anti-symmetric) but we can omit the details. What we wish to suggest is that the notion of minimal truthmakers can be understood in terms of a liberal notion of parthood, and that this is one way to solve the problem raised for the initial formulation of D1. 
The second response is to accept that some portions of reality can be more or less encompassing but not differ regarding their parts (understood classically), and to adapt the definition of minimal truthmakers accordingly:

D2: $T$ is a minimal truthmaker for $p={ }_{\mathrm{df}} T$ fully makes $p$ true and (a) either (i) $T$ is such that it has no proper parts, or (ii) no proper part of $T$ fully makes $p$ true, and (b) either

(iii) $T$ is such that it has no non-mereological constituents, or (iv) no non-mereological constituent of $T$ fully makes $p$ true. $^{8}$

This definition is to a certain extent provisional, since it relies on the notion of 'nonmereological constituents' which we have not defined. However, we think this notion is not completely mysterious. As paradigm instances of entities with non-mereological constituents, we would mention states of affairs (see Armstrong 1997, 118-127).

In what follows we leave the choice between D1 (understood either in terms of classical mereology or Fine's pluralism) and D2 open. The aim of this discussion is to illustrate that the definition of minimal truthmakers is not as straightforward as it might appear at first glance, but that nevertheless a number of options are available depending on one's preferred ontology. The choice between these ontologies is not a matter to be settled by appeal to truthmakers, minimal or otherwise.

\section{III}

We suggest that the idea of minimal truthmakers as defined above has plausible applications. Consider the following situation: there are exactly three bottles of beer in the fridge. Prima facie, this fact is a minimal truthmaker for the proposition, 'There are three bottles of beer in the fridge' (Rodriguez-Pereyra cites similar cases in 2006, 970-973). Were any of 
the bottles to be removed or destroyed without being replaced, the resulting state of affairs would no longer make the proposition true. Furthermore, a proposition can have more than one minimal truthmaker; e.g., the proposition 'There is at least one bottle of beer in the fridge' has at least as many minimal truthmakers as there are bottles of beer in the fridge.

Not every true proposition has a minimal truthmaker, and some propositions, if true, necessarily cannot have one. For example, if there are infinitely many electrons, then all the existing electrons make the proposition 'There are infinitely many electrons' true, but so does the group consisting of every second electron, the group consisting of every fourth electron, etc. ${ }^{9}$ This is because of the specifics of that situation: the notion of minimality is not applicable to certain kinds of infinite sequence which have other infinite sequences as parts. Schaffer refers to cases like this in criticising the notion of minimal truthmakers (2010, 314). However, we are not committed to the view that all truths must have minimal truthmakers, or even that all truths with truthmakers must have minimal truthmakers. Cases such as these limit the application of the notion of minimal truthmakers, rather than showing it to be without application.

Some of the most promising applications of the concept of minimal truthmakers concern fundamental particles such as electrons. Fundamental particles are natural candidates to be minimal truthmakers because they are plausible candidates to be 'least encompassing' portions of reality. Consider the proposition 'There is at least one electron'. Let us assume that electrons are fundamental particles and the concept 'electron' carves at the joints. What makes 'There is at least one electron' true is the existence of any single electron. If fundamental particles have no proper parts, nothing short of an electron could make true the proposition 'There is at least one electron'. That is, any electron is a minimal truthmaker for this proposition. 
It may be objected here that even supposed fundamental particles may have further proper parts. This could be the case if the world is 'gunky', i.e. made of atomless gunk which can be divided ad infinitum. Schaffer mentions gunk as a problem for minimal truthmakers (2010, 314). If each of the infinite proper parts of something is homogenously pink, it seems impossible to find a minimal truthmaker for a proposition such as 'Something is homogeneously pink’. However, Sider insists that concepts such as ‘electron’ carve at the joints even in gunky worlds - that is, they match genuine differences in reality which are not dependent on the decisions or interests of any subjects (Sider 2011, 133-135; see also O’Conaill and Tahko 2012). This may offer a way to save at least some minimal truthmakers in gunky worlds - electrons may be minimal truthmakers for propositions featuring the concept 'electron' because even though they have proper parts, nothing short of an electron can make true a proposition about electrons.

However, we do not think that only mereological simples could act as minimal truthmakers. There are also cases where complex portions of reality are the least encompassing truthmakers for a proposition. Consider the proposition 'There is a border between France and Germany'. In this case, the minimal truthmaker of the proposition would seem to be an agreement between France and Germany (which, we might add, could easily go out of existence). In other words, nothing short of an agreement would suffice for a border, and the agreement itself makes the proposition true, although maintaining the border's effectiveness might require further institutions and arrangements. Examples such as this suggest that the notion of minimal truthmaker need not be limited to mereological simples such as fundamental particles. 
In this section we shall assess Armstrong's claim that minimal truthmakers are of special importance for metaphysics. We agree with Armstrong that minimal truthmakers have a useful role in metaphysics, but our reasons for thinking so are different, as will become clear in subsequent sections.

Armstrong regards truthmaker theory in general as 'a promising way to regiment metaphysical inquiry’ $(2004,4)$. In arriving at metaphysical results, one must start with (what one takes to be) truths, and then ask what truthmakers they demand $(2004,26)$. One result of such regimentation is candour with regard to one's ontological commitments, given which propositions one holds true: 'the truthmaker insight, as I take it to be, prevents the metaphysician from letting dispositions “hang on air” as they do in Ryle’s philosophy of mind.' (Armstrong 2004, 3; see also Heil 2012, 170). ${ }^{10}$

However, it is not clear how the truthmaker insight can be refined in the specific case of minimal truthmakers. A natural suggestion might be that the minimal truthmakers for the propositions one holds true capture one's core ontological commitments: that is, whatever else one is committed to in holding these propositions true, one must at least be committed to accepting the existence of the minimal truthmakers for those true propositions which are suitable to have them (e.g., leaving aside cases such as infinitely many electrons). Anything else is an extra, something beyond this core commitment. On this approach, minimal truthmakers are something like the result of applying Occam's Razor to truthmaker theory (see Schaffer 2008, 15; Cameron 2008, 5 n. 7).

Armstrong suggests something very similar to this. He distinguishes between propositions with multiple minimal truthmakers (e.g., 'At least one human exists'), and those with unique minimal truthmakers (e.g., for every truthmaker $x$, the proposition ' $x$ exists' has $x$ 
as its unique minimal truthmaker). ${ }^{11}$ Armstrong's suggestion is that the truths which have unique minimal truthmakers will be fundamental to each metaphysical position $(2004,24)$.

We do not wish to completely dismiss this way of defending minimal truthmakers. However, neither shall we rest our argument upon it. First, we are not sure what parsimony it effects, given that a single entity can make many propositions true. For instance, suppose one accepts the truth of the propositions ' $x$ exists' and ' $y$ exists'; and suppose that $x$ is a minimal truthmaker for the first proposition, $y$ is a minimal truthmaker for the second, but that $y$ is also a non-minimal truthmaker for the first proposition. In this case, one will be committed to the existence of two minimal truthmakers, but also to a non-minimal truthmaker for one proposition. Therefore, committing oneself to minimal truthmakers does not rule out allowing non-minimal truthmakers into one’s ontology. Given this, and given that one will presumably accept the truth of a great many propositions, we are unconvinced that regimenting one's ontological commitments by minimal truthmakers (or even unique minimal truthmakers) will have much impact on the entities to which one will be committed. ${ }^{12}$

Second, Armstrong notes that the list of the unique minimal truthmakers a particular thinker posits will simply reproduce the list of propositions of the form ' $x$ exists' which that thinker accepts as true (and which they take to have truthmakers). So the move from the list of propositions of this form to the list of their unique minimal truthmakers does not take us very far. Indeed, it arguably does nothing that cannot be achieved by existential quantification (cf. Schaffer 2008, 16). ${ }^{13}$

Third, it is not clear that the core ontological commitments of a theory can always be captured solely by appeal to minimal truthmakers. Since at least some true propositions have truthmakers but no minimal truthmakers, it seems possible that some theories could necessarily involve propositions which could not have minimal truthmakers (as in the case of an infinity of electrons discussed earlier). It would be ad hoc to insist that none of the core ontological 
commitments of these theories could be expressed by these propositions. If the notion of a core ontological commitment comes to anything on the truthmaker view, it requires being committed to those entities which make true the propositions which are required for the theory one holds (e.g., Cameron 2010). ${ }^{14}$

\section{$\mathbf{V}$}

We shall now propose a different reason for thinking that the notion of minimal truthmakers can be of metaphysical use. As our point of departure, we endorse the following description offered by Molnar: 'Truthmaker theory is a theory of the groundedness of truthvalues. Minimally, such a theory should enable one to identify whatever it is that explains why the truth-bearers have the truth-values they have’ $(2000,82) .{ }^{15}$ Molnar's minimal requirement is that truthmakers do explanatory work. The data to be explained are the truth-values of specific propositions; one of the tasks of truthmaker theory is to identify what explains this data. $^{16}$

We do not wish to suggest that only minimal truthmakers can meet Molnar's requirement. Rather, we shall argue that if one accepts Molnar's requirement, then minimal truthmakers play an important explanatory role. In defending this claim we shall make two further assumptions: that one of the desiderata of an explanation is precision, and that the most precise explanation of the truth-value of a proposition is provided by the most discerning truthmaker for that proposition (roughly, the truthmaker for that proposition which makes true the fewest other propositions). In what follows, we shall expand on these assumptions and argue that minimal truthmakers are the most discerning truthmakers. ${ }^{17}$

To set about meeting Molnar's requirement, one might begin as follows: given a set of propositions $P$ and a set of entities which are candidate truthmakers $T$, one of the tasks of truthmaker theory is to work out which members of $T$ are relevant to the truth of which 
members of $P$. An entity $x$ is relevant to the truth of a proposition $p$ if and only if $x$ is among p's truthmakers. ${ }^{18}$ Since truthmaking is not a one-one relation, for a given true proposition in $P$ we ought not to expect that only one member of $T$ will be among its truthmakers, or viceversa. For example, if $p$ is the proposition 'The ball is red', then the colour of the ball, the overall physical state of the ball, and the overall physical state of the universe all seem relevant to the truth of $p$.

We suggest that listing the truthmakers for a given proposition meets Molnar's requirement only to a limited extent. To fully meet this requirement, to explain 'why the truthbearers have the truth-values they have', requires specifying the truthmakers which make each proposition as opposed to the others true. If $p$ and $q$ are different members of $P$, and if some items in $T$ are relevant to the truth both of $p$ and of $q$, then listing these items will not tell us what it is which makes $p$ true as opposed to $q$, or vice-versa. There is a sense in which we would have explained the truth of $p$ and of $q$, by listing the relevant truthmakers in each case. However, this explanation would suffer in comparison with a more precise account, one which involves 'discriminating sufficiently finely between the truth-makers of different propositions' to say what makes each proposition true rather than the other (Lowe 2009, 201). ${ }^{19}$

The point can be put as follows: in order to fully discharge Molnar's requirement, we need to offer as precise an explanation as possible of the truth of each proposition. However, different truthmakers can be more or less discerning; that is, some truthmakers make more propositions true than others. Armstrong describes the world as 'the least discerning of all truthmakers', noting that it 'makes every truth true, or failing that, every truth that has a truthmaker true' $(2004,18)$. It is in this sense that the world is an uninteresting truthmaker: since it can be appealed to in order to explain the truth of any true proposition, it cannot help us to say what makes one proposition true as opposed to any other. ${ }^{20}$ In order to provide a more 
precise explanation of the truth of a given proposition, we need to appeal to a more discerning truthmaker for that proposition.

In defence of the need for precision, note that it is widely agreed that any serious account of truthmaking must be able to discriminate to some degree between the truthmakers for different truths (see Restall 1996, 334-335; Molnar 2000, 82-83; Armstrong 2004, 11; Rodriguez-Pereyra 2006, 959-960, 963-965; Lowe 2006, 203). To accept this assumption is to accept precision as a desideratum of truthmaker theory. This does not entail that every proposition must have a minimal truthmaker, or that only minimal truthmakers can provide a precise explanation of the truth-values of propositions. Rather, we shall argue that minimal truthmakers provide the most precise explanation possible. ${ }^{21}$.

Thus far we have glossed the idea of more or less discerning truthmakers as entities which make fewer or more propositions true. Discernment can be characterised more formally as follows:

(DC) An entity $x$ is the most discerning truthmaker for a proposition $p$ if $x$ fully makes $p$ true, and if there are no other entities which fully make $p$ true and act as full truthmakers for fewer other propositions than $x .^{22}$

It is important to note that (DC) does not apply in all cases; that is, it cannot always be said that $x$ is the most discerning truthmaker for $p$, tout court. ${ }^{23}$ Rather, we can apply the idea of discernment to a finite set of entities $T$ and a finite set of propositions $P .{ }^{24}$ A member of $T$, $x$, is the most discerning truthmaker of a member of $P, p$, if $x$ fully makes $p$ true, and if $x$ fully makes true fewer other members of $P$ than any other member of $T$ which fully makes $p$ true. As an example of an application of (DC), suppose that a tomato's colour is part of its overall physical makeup. Any propositions made true by the tomato's colour will be made true by its 
overall physical makeup, but the latter will also make true other propositions (e.g., concerning the tomato's shape) to which the colour has no relevance. Therefore, the tomato's colour is the more discerning truthmaker.

We have argued that if there is an explanatory constraint on truthmaker theory then one desideratum of such a theory would be to find the most precise explanation possible for the truth of each proposition. We have further argued that the most precise explanation for the truth of a proposition $p$ will be provided by the most discerning of $p$ 's truthmakers. We can now connect this line of thought to the notion of minimal truthmakers: if $p$ has an entity $x$ as its most discerning truthmaker, $x$ will be the minimal truthmaker for $p$. Armstrong remarks 'The more embracing the truthmaker, the less discerning it is' $(2004,18)$. We suggest that this equivalence runs both ways: the less embracing a truthmaker is, the more discerning it will be. Those truthmakers are minimal which embrace the least amount of reality. These are the most discerning of all truthmakers.

VI

We have argued that minimal truthmakers play an important role in truthmaker theory, as they provide the most precise explanations for the truth of different propositions. This importance is limited in two ways: not all truths have minimal truthmakers; and in many cases the truth of a proposition can be explained to some degree by appealing to its non-minimal truthmakers. But since one of the tasks of truthmaker theory is to explain the truth-values of different propositions, and since precision is a desideratum of such explanations, the truthmaker theorist cannot afford to ignore minimal truthmakers. In this section we will put minimal truthmakers to use in the manner suggested by the previous argument.

We suggest that a precise explanation of the truth-value of a given proposition involves the following: (a) identifying what makes that proposition, as opposed to other propositions, 
true (provided that proposition has a truthmaker); ${ }^{25}$ and (b) if that proposition is contingent, identifying what makes it true in certain situations and what makes it false in others. An account which answers these questions would effectively meet Molnar's explanatory requirement. In this section we shall consider the relevance of minimal truthmakers to (a) and (b) respectively. In this way, we shall meet the challenge Schaffer poses for defenders of minimal truthmakers: to provide a reason to posit them by showing what useful role they would play $(2010,315)$.

As regards (a), the issue can be stated as follows: if $p$ and $q$ are each true, what is it which makes $p$ as opposed to $q$ true? We accept that it is possible for multiple propositions to be made true by the same truthmaker. But it is often possible to ask what it is about such a truthmaker which makes true one proposition as opposed to another. For example, it is correct to say that the physical state of the ball makes true both 'The ball is round' and 'The ball is red'. But one seems entitled to ask what it is about the ball which makes the first of these propositions, as opposed to the second, true. One's truthmaker theory will be uninformative to the degree that it cannot answer this question (cf. Rodriguez-Pereyra 2000, 268-269).

When one tries to identify what it is which makes $p$ true, the most precise answer available will be the minimal truthmaker(s) for $p$, provided some can be found. For example, if $p$ is 'There is at least one bottle of beer in the fridge', the fact that there is a bottle of beer in the fridge provides a more precise explanation of the truth of $p$ than the fact that there are seventeen bottles in the fridge, or the physical state of the fridge and its contents. One can ask what it is about the fact that there are seventeen bottles in the fridge, the state of the fridge, etc., in virtue of which $p$ is true. The answer to each of these questions will ultimately lead to the fact that there is a bottle of beer in the fridge, as this is the most precise explanation for the truth of $p$.

Issue (b) concerns differences in the truth-value of one and the same proposition. Here it will be useful to contrast our view with Schaffer's (2010) defence of truthmaker monism, the 
view that the only truthmaker is the entire world. Consider the following case: proposition $p$ is true at world $w$ but false at world $w$ '. Schaffer accepts that truth-values need explaining, but argues against the suggestion that we need to appeal to anything more minimal than different worlds in order to explain the difference in $p$ 's truth-value: 'One world $w$ might make $p$ true, and another world $w^{\prime}$ might make $p$ false. This is a difference between the worlds $w$ and $w^{\prime}$. The difference between truth and falsity is due to the world' $(2010,317)$.

Clearly there must be some difference between $w$ and $w$ ' in order that this difference in p's truth-value be explained; but which difference? There might be any number of differences between $w$ and $w^{\prime}$. An explanation of the truth-value of $p$ should be able to specify the difference or differences between these worlds that are relevant to the truth of $p$. Simply to note as Schaffer does that there is a difference between $w$ and $w^{\prime}$ is not enough, contrary to his suggestion, to explain the difference in truth-value.

Specifying any differences between the worlds relevant to the truth of a proposition will provide a better account than Schaffer's, but again it is minimal truthmakers which provide the most precise explanation. If the proposition 'There is at least one bottle of beer in the fridge' is true in world $w$ but false in $w^{\prime}$, it would be correct to say that this is because the physical makeup of $w$ is different to the makeup of $w^{\prime}$, or because the physical makeup of the fridge is different in each world. But neither of these explanations would be as precise as that afforded by referring to the difference in the number of beer bottles in the fridge between $w$ and $w$ '.

\section{VII}

In this final section we shall consider possible objections to the proposed account of minimal truthmakers. To begin with, it might be objected regarding the example just given that we have not correctly identified the minimal truthmaker. For example, someone might suggest that a more minimal truthmaker for $p$, 'There is at least one bottle of beer in the fridge', could 
be found by considering the parts of the bottle. It might be suggested that $p$ is fully made true by the fact that there is a bottle minus one molecule in the fridge; and this fact looks more minimal than the fact that there is one bottle in the fridge. ${ }^{26}$

This kind of objection raises three possibilities: (i) the collection of molecules which remains after the subtraction of a molecule is not sufficient to constitute a bottle of beer; (ii) the remaining collection of molecules is sufficient to constitute a bottle of beer; (iii) it is indeterminate whether or not the remaining collection of molecules is sufficient to constitute a bottle of beer. In the case of (i), the fact that the remaining collection of molecules is in the fridge fails to constitute a full truthmaker for $p$, and so cannot constitute a minimal truthmaker. In the case of (ii), the fact that the collection of molecules is in the fridge suffices to constitute a full truthmaker for $p$. But this doesn't show that we are wrong to suggest that the fact that there is a bottle of beer in the fridge is the minimal truthmaker for $p$, since ex hypothesi it is the same fact which is making $p$ true (what has changed is the material constitution of the bottle of beer, but not the fact that there is a bottle of beer). Essentially, the problem represented by (i) and (ii) is the problem of what constitutes a bottle of beer. As long as it is the case that there is a sharp cut-off as to when a collection of molecules constitutes a beer bottle, then the minimal truthmaker could be considered to be the fact that there is a bottle of beer in the fridge, whatever its constitution happens to be.

However, if parthood is vague, and we use parthood to define minimal truthmakers, then putative minimal truthmakers will be vague. This leads us to (iii): if there is no sharp cutoff as to when a collection of molecules constitutes a beer bottle, then we would seem to be dealing with genuine metaphysical vagueness. We have two responses to offer to this sort of possibility. First, we would insist that in the case of (iii), $p$ is not fully made true by that state of affairs (the state of affairs of some object, constituted by the remaining collection of molecules, being in the fridge). We assume that a proposition is fully made true by an entity 
only when it is determinate that this entity is sufficient to make the proposition true. In the case of (iii), since it is not determinate whether the collection of molecules is sufficient to constitute a bottle of beer, it is not determinate whether or not the situation is one in which there is a bottle of beer in the fridge; therefore, $p$ is not fully made true by this state of affairs. ${ }^{27}$

Second, we suggest that in this case the vagueness is plausibly conceptual or linguistic (specifically, the vagueness of the concept 'bottle', when considered in terms of what would count as a collection of molecules sufficient to constitute something falling under that concept). ${ }^{28}$ If this is correct, then we need a precisification of the concept 'bottle' before attempting to judge borderline cases, but in normal circumstances it is easy to determine whether there is a bottle of beer in the fridge or not.

It might be further objected that if all propositions turn out to be metaphysically vague, then our response to the argument we have just been considering would entail that there are no minimal truthmakers. This would be a worrying development, but we consider it unlikely that all propositions are metaphysically vague. Specifically, if there are fundamental scientific predicates such 'electron' that carve reality at its joints (following Sider; see section III), then propositions involving these predicates are plausibly not subject to vagueness. Moreover, even if some vagueness were to remain, it may still be possible to introduce a class of 'nearlyminimal' truthmakers. For instance, even if there is some vagueness involved with the notion of 'electron', it may still be a viable candidate for a minimal truthmaker, e.g. for the proposition 'There is at least one electron.' This is because there is likely to be an upper limit or cut-off point to the richness of the concept 'electron' in such a way that any addition will not make a difference to the truth of 'There is at least one electron'. That is, we can compensate for the vagueness of 'electron' if we adopt a type of supervaluationism: there are many precise concepts of 'electron' which resemble each other, and if we encompass all of these concepts, then any further addition will not make a difference to the truth of 'There is at least one electron.' 
Finally, even if it turns out that there are no minimal truthmakers we would still argue that the concept of a minimal truthmaker can play a useful role in metaphysics. For one thing, it would allow us to state the fact that the world is such that there are no minimal truthmakers, which would itself be of metaphysical interest. More generally, the notion of a minimal truthmaker could function as a limit case, allowing us to understand explanations of the truthvalues of different propositions as more or less precise. Finally, if we assume that there could be minimal truthmakers even if there were none in the actual world, then the notion of minimal truthmakers would seem to be useful at least in the sense that it will help to specify what the most precise explanation is for truths of propositions in worlds where there are minimal truthmakers. ${ }^{29}$

We have clarified the notion of minimal truthmakers and argued that there are strong intuitive and explanatory reasons to continue using this notion. Furthermore, we have attempted to demonstrate that there are plausible candidates for minimal truthmakers, especially in the case of fundamental particles. Further work is required to specify which truthmakers are minimal in given cases, and to determine how broadly the notion applies, but we have outlined at least the beginnings of a systematic account. ${ }^{30}$

\footnotetext{
NOTES

${ }^{1}$ For further discussion of truthmaking in metaphysics, see Beebee and Dodd (2005), and Lowe and Rami (2009).

${ }^{2}$ We shall use ‘entity' to denote anything with existence or identity conditions. We assume that propositions are truthbearers, but what we say about them applies equally to other possible truthbearers.

${ }^{3}$ We shall sometimes refer to a partial truthmaker for a proposition as partially making that proposition true, and a full truthmaker as fully making it true.

${ }^{4}$ This argument assumes that minimal truthmakers can be defined in terms of proper parts. We shall consider the definition of minimal truthmakers in the next section.
} 
${ }^{5}$ In addition to the points we raise in the main text, it is not clear how this argument would apply to truths which cannot have minimal truthmakers (see section III). It is for this reason that Rodriguez-Pereyra, while rejecting (M), accepts the possibility of non-minimal truthmakers (2006, 978-979).

${ }^{6}$ This formulation is similar to those offered by Rodriguez-Pereyra (2006, 978-979); Horwich (2009, 187); and Rami (2009, 24). For slightly different formulations also offered in terms of parts, see Restall 1996, 332, and Schaffer 2010, 313.

${ }^{7}$ Though the application of the notion of minimality to states of affairs has been queried by Schaffer (2008, $15 \mathrm{n}$. 7).

${ }^{8}$ That is, $T$ must meet either (i) or (ii), and it must meet either (iii) or (iv).

9 This example is slightly adapted from that originally offered by Restall and cited in Armstrong 2004, 21-22.

${ }^{10}$ This point is sometimes described as the idea that truthmaker theory aims to 'catch cheaters' (see Schaffer 2010, 312).

${ }^{11}$ See Armstrong 2004, 23. For criticism of this assumption, see Cameron 2008.

12 This is not to say that this strategy would have no impact. It might rule out, for instance, appeals to disjunctive or conjunctive states of affairs as truthmakers. However, there are other grounds for ruling out entities of this sort. What we would need in order to endorse a role for minimal truthmakers in regimenting ontological commitments is an example of an important ontological regimentation which could only be provided by appealing to minimal truthmakers. We do not have any such example in mind, but pending its discovery we shall not defend minimal truthmakers in this way.

${ }^{13}$ For this reason Armstrong's approach might be questioned along the lines suggested by Heil's criticism of Quine as trying to uncritically read off ontological commitments from the truths one accepts (2012, 163-168).

${ }^{14}$ Cameron claimed in his 2008 that the proposition 'There are denumerably many things' has no ontological commitments, because it has no minimal truthmakers (5, n. 7). More recently he has revised this view, accepting that the truth of such a proposition would commit one to the existence of some denumerable plurality of entities as its truthmaker (2010, 253-254). While this position might allow one's ontological commitments to be captured by truthmakers, it would entail giving up any hope of capturing one's ontological commitments by minimal truthmakers only.

${ }^{15}$ A similar desideratum for truthmaker theory is expressed by Rodriguez-Pereyra: ‘discriminating which entities make which propositions true' (2006, 964; see also Armstrong 2004, 8; Lowe 2006, 182). The idea that a 
truthmaker principle should yield informative explanations is questioned by Lewis (2001, 611-612) and Rami $(2009,5)$.

${ }^{16}$ While we assume that truthmaker theory should meet certain explanatory requirements, this is not to say that we understand what it is for something to be a truthmaker by appealing to those explanatory requirements. Rather, the fact that the truth of $p$ can be explained by appealing to its truthmakers is a consequence of the fact that $p$ is made true by these entities (Rodriguez-Pereyra 2009, 236, 242).

${ }^{17}$ The desire for more discerning truthmakers is not novel in itself, but as far as we are aware it has not been systematically connected to minimal truthmakers in the way we propose.

${ }^{18}$ It is worth noting that relevance and minimality are not one and the same. An entity is relevant to the truth of a given proposition $p$ if it either fully or partially makes $p$ true; but a minimal truthmaker for $p$ must fully make it true.

${ }^{19}$ That is, we are assuming that precision is a desideratum for any explanation of the truth-value of a proposition. It does not follow that it is the only such desideratum. Nor is a less precise explanation completely inadequate; our point is simply that it is not as good, other things being equal, as a more precise explanation.

${ }^{20}$ This suggestion has recently been questioned by Schaffer (2010). While we will not be able to answer every point he raises in the present context, we shall address some of his arguments against minimal truthmakers in the next section. For further discussion, see Fisher (forthcoming), where an account of minimal truthmakers is defended. We learned about this paper only after the present paper was written, so we cannot engage with it further, but we believe that this serves to highlight our claim that minimal truthmakers deserve further attention.

${ }^{21}$ Precision in explanation also seems closely related to other desiderata, in particular informativeness. Other things being equal, the most precise explanation will be the most informative. Therefore, it may be that minimal truthmakers provide the most informative explanation of the truth of the propositions they make true. Thanks to an anonymous referee for Pacific Philosophical Quarterly for bringing this possible link to our attention.

${ }^{22}$ Here, 'other propositions' are not considered to involve trivial truths which incorporate $p$ (such as disjunctions) or propositions whose truth depends on the truth of $p$, e.g., $q$ ('It is true that $p$ '), $r$ ('It is true that $q$ '), etc. We refer to 'the most discerning truthmaker', but some propositions will have numerous truthmakers which are each as discerning as the others. In these cases one may speak of 'the most discerning truthmakers'. Also, we assume that 'the most discerning truthmaker' applies only to entities in a given world. It may be that a proposition $p$ has more discerning truthmakers in other worlds, but we shall not discuss such cases. 
${ }^{23}$ For instance, if two entities are such that each makes true an infinite set of propositions and neither of these sets can be nested inside the other, then it cannot be said that one set is larger than another and thus the notion of discernment cannot apply.

${ }^{24}$ The notion of discernment can also be applied to entities which make infinite sets of propositions true, provided these sets can be nested inside each other. In this case, we can use ordinality to compare the different sets of propositions to see if they are of different sizes.

${ }^{25}$ If there are true propositions which do not have truthmakers, we doubt whether an explanation can be provided for their being true.

${ }^{26}$ Armstrong raises a similar worry $(2004,21)$.

${ }^{27}$ It may be possible to settle the indeterminacy problem in other ways. For instance, we might say that a collection of molecules constitutes a bottle of beer, and hence can help to make up a minimal truthmaker for $p$, only if it is capable of behaving in a manner which we would expect a bottle of beer to behave (allowing one to quench one's thirst, etc.). In many cases this behaviour can be determined in terms of having causal powers relevant to the context of the utterance of sentences expressing $p$. See Tahko (2009) for further discussion on this type of solution to problems of vagueness.

${ }^{28}$ See Stanley 2003. For an alternative approach to this kind of issue, see Lowe’s discussion of Horgan and Potrč in his 2012.

${ }^{29}$ Thanks to an anonymous referee for Pacific Philosophical Quarterly for this suggestion.

${ }^{30}$ We wish to thank Jamin Asay, Alex Carruth, Kathrin Koslicki, Ciaran O’Conaill, Olley Pearson, Tobias Wilsch, the audience at the Durham departmental seminar and an anonymous referee for Pacific Philosophical Quarterly for helpful comments on earlier versions of this paper.

\section{REFERENCES}

Armstrong, D. M. (1997). A World of States of Affairs. (Cambridge: Cambridge University Press).

Armstrong, D. M. (2004). Truth and Truthmakers. (Cambridge: Cambridge University Press). Beebee, H. and Dodd, J. (eds.) (2005). Truthmakers: The Contemporary Debate. (Oxford: 
Oxford University Press).

Cameron, R. P. (2008). “Truthmakers and Ontological Commitment: Or How to Deal with Complex Objects and Mathematical Ontology without getting into Trouble” Philosophical Studies 140 (1): 1-18.

Cameron, R. P. (2010). “How to have a Radically Minimal Ontology” Philosophical Studies 151 (2): 249-264.

Fine, K. (2010). “Towards a Theory of Part” Journal of Philosophy 107 (11): 559-589.

Fisher, A. R. J. (forthcoming). "Priority Monism, Partiality, and Minimal Truthmakers” Philosophical Studies. DOI: 10.1007/s11098-014-0314-z.

Heil, J. (2012). The Universe as We Find It. (Oxford: Oxford University Press).

Horwich, P. (2009). “Being and Truth”, in Lowe, E. J. and Rami, A. (eds.) Truth and TruthMaking. (Stocksfield: Acumen), pp. 185-200.

Lewis, D. (2001). “Truthmaking and Difference-Making” Noûs 35 (4): 602-615.

Lowe, E. J. (2006). The Four-Category Ontology: A Metaphysical Foundation for Natural Science. (Oxford: Oxford University Press).

Lowe, E. J. (2009). “An Essentialist Approach to Truth-making”, in Lowe, E. J. and Rami, A. (eds.) Truth and Truth-Making. (Stocksfield: Acumen), 201-216.

Lowe, E. J. (2012). “Against Monism” in Goff, P. (ed.) Spinoza on Monism. (London/New York: Palgrave Macmillan), pp. 92-112.

Lowe, E. J. and Rami, A. (eds.) (2009). Truth and Truth-Making. (Stocksfield: Acumen).

Martin, C. B. (1980). "Substance Substantiated” Australasian Journal of Philosophy 58 (1): $3-10$.

Molnar, G. (2000). “Truthmakers for Negative Truths” Australasian Journal of Philosophy 78 (1): 72-86.

O’Conaill, D. and Tahko, T. E. (2012). “On the Common Sense Argument for Monism”, in 
Goff, P. (ed.) Spinoza on Monism. (London/New York: Palgrave Macmillan), pp. 149-166.

Rami, A. (2009). "Introduction: Truth and Truth-Making” in Lowe, E. J. and Rami, A. (eds.) Truth and Truth-Making. (Stocksfield: Acumen), pp. 1-36.

Restall, G. (1996). “Truthmakers, Entailment and Necessity” Australasian Journal of Philosophy 74 (2): 331-340.

Rodriguez-Pereyra, G. (2000). “What is the Problem of Universals?” Mind 109 (434): 255273.

Rodriguez-Pereyra, G. (2006). “Truthmaking, Entailment, and the Conjunction Thesis” Mind 115 (460): 957-982.

Rodriguez-Pereyra G. (2009). “Why Truth-Makers?” in Lowe, E. J. and Rami, A. (eds.) Truth and Truth-Making. (Stocksfield: Acumen), 227-241.

Schaffer, J. (2008). “Truthmaker Commitments” Philosophical Studies 141 (1): 7-19.

Schaffer, J. (2010). “The Least Discerning and Most Promiscuous Truthmaker” Philosophical Quarterly 60 (269): 307-324.

Sider, T. (2011). Writing the Book of the World. (Oxford: Oxford University Press).

Simons, P. (1992). “Logical Atomism and Its Ontological Refinement: A Defense”, in Mulligan, K. (ed.) Language, Truth and Ontology. (Dordrecht: Kluwer).

Stanley, J. (2003). “Context, Interest Relativity and the Sorites”, Analysis 63 (4): 269-281.

Tahko, T. E. (2009). “Against the Vagueness Argument”, Philosophia 37 (2): 335-340. 